\title{
Mixing Educational Robotics, Tangibles and Mixed Reality Environments for the Interdisciplinary Learning of Geography and History
}

\author{
https://doi.org/10.3991/ijep.v9i2.9950 \\ Stefanos Xefteris $\left.{ }^{(}\right)$, George Palaigeorgiou \\ University of Western Macedonia, Florina, Greece \\ sxefteris@uowm.gr
}

\begin{abstract}
In the present study we present a mixed reality learning environment that aims to become a creative, joyful and efficient interdisciplinary canvas for learning about history and geography and for concurrently fostering computational thinking. The environment makes use of embodied affordances and educational robotics and consists of two parts: an augmented 3D-tangible model of southern Europe with finger-based interaction and a second floor-based augmented robotics track depicting European landmarks, where students are asked to perform tasks with Mindstorms EV3 robots. The game scenario describes a treasure hunt around Europe and students swap between finger-based and robotics-based interactive surfaces in two pairs. We evaluated our intervention with pre-service teachers in six groups of three or four who played with the environment for approximately 45 minutes each. Data collection was performed through pre- and post-knowledge test, attitude questionnaire and a semi-formal group interview. The answers showed that the mixed reality environment improved motivation, engagement and enhanced their orientation around Europe's geophysical features. The robotics aspect consolidated further their computational thinking skills while being highly exciting. The proposed approach was closer to the preservice teacher's expectations and interactive experiences, exploited embodied learning opportunities and gamified the learning process.
\end{abstract}

Keywords-Mixed reality, tangible interfaces, educational robotics, geography learning, history learning

\section{Introduction}

It is not unusual for people to think history as a subject, as no more than a series of facts and timelines, disregarding its deeper, more fundamental learning value: By learning history we are provided with anchors that link the present to our collective past and knowledge that is not restricted to it, but can also be used to foster understanding of how the current society and status quo evolved through time. More often than not, this knowledge is also useful in our own life, facilitating informed decisions. Through learning history, students are enabled to disregard ex-cathedra or unsubstantiated explanations since current teaching paradigms aim to ensure that the root causes of facts are 
identified, thus promoting a better understanding. Although history is fascinating and a worthwhile endeavor, quite a few students would disagree: Learning about history was frequently deemed by them as an uninteresting and boring activity, owed to the fact that up until recently, teaching of history included mainly the endless recitation of dates, facts and events [1]. Students have always had trouble developing their historical understanding, limiting it to just the presented facts, and misinterpreting them out of historical context. Studies conducted in many schools, have shown significant fluctuations on the pupils' attitudes towards history [2].

Although there is evidence that students can learn to employ certain methodologies used by historians, it is apparent that more often than not, students fail to surpass a superficial level of processing historical evidence. For example, when examining a historical source, students may fail to discover the provided content or use it out of context. But the extant barriers are not limited to using historians' heuristics. There is also evidence that the differences in applying scientifically robust methodologies in history learning are also owed to the students cognitive development, pre-existing knowledgebase and experience and personal views of the world [3]. Learning history, nowadays, involves actual research and evaluation of historical sources and letting students reach conclusions based on accumulated evidence, tackling both the methodological and the cognitive barriers [4].

History teaches us about the past; it is fundamentally linked to time. But time without space is meaningless. To make the big picture complete, we also need the spatial dimension that completes history's temporal one. This is provided by geography, which creates a symbiotic relationship with history. Without each other, none is intelligible [5]. One of the pillars of early education is the development of geographical literacy, which in recent years has been greatly influenced and improved by the integration of ICT in school curricula. Geography related activities have evolved into appealing and authentic experiences. Students are now navigating interactively through $2 \mathrm{D}$ and $3 \mathrm{D}$ data on a screen or going on virtual trips through VR gear and can access huge geophysical databases. The integration of ICT makes immersion easier and improves observation, discussion and analysis [6]. The current research focus is to promote interdisciplinary teaching methods that combine History with Geography (and Maths, Art, Music) which can be instrumental in increasing student motivation and learning effectiveness on all related domains [7].

Tangible learning refers to learning with physical objects -manipulatives-, which can range from wooden blocks to advanced robotics. Tangible interfaces build on tangible learning and transform digital data to a physical form and concurrently, a digital entity to physical forms. This coupling of the digital and the physical in a seamless looping feedback, enables users to interact naturally with the digital aspect, through bodies drawing on a highly developed kinesthetic intelligence. In this frame of reference, tangible physical maps can significantly foster the development of novel teaching scenarios. Tangible physical maps complement and advance digital cartography (usually represented in screens) and become an invaluable tool for teaching geography in an embodied way. Tangible interfaces promote a sensory engagement of the student and the facilitation of spatial tasks while actively manipulating a digital representation of physical objects $[6,8]$. On the other hand, a virtual "finger trip" over a tangible, interactive 
and augmented environment depicting historical sites seems to motivate students to engage deeper into the study of historical content [9].

Robotics can also add value to mixed reality tangible interfaces in a "shared reality" concept. This concept ensures maintenance of perceptual continuity by applying the laws of material reality to the simulated world's physical laws[10]. Robots act as an extra tangible interface to the mixed reality landscape and function as an agent to the virtual world. Beyond the physicality of the robot, the addition of robotics in a mixed reality scenario enhances the students' computational thinking skills [11]. The integration of robotics in learning environments facilitates the development of high order thinking processes (decomposition, abstraction, pattern recognition, algorithm design) and enables students to improve their problem solving skills [12]. The positive effects of the introduction of robotics on students' learning have been extensively reported. Some of the impacts include increased understanding of how technological and scientific precepts and applications help solve real world problems, enhanced learning on programming, physics, mechanical engineering and science as well as increased confidence in using technology [11]. Moreover, educational robotics provide a rich potential for team building and social skills development, enabling students to experiment and create on their own.

In this article, we present a two-layered tangible environment integrating two mixed reality environments that aim to enhance and improve the experience of learning geography and history but also to promote practicing computational thinking tasks. The proposal tries to introduce an interdisciplinary approach for engineering pedagogy with the introduction of two interactive distinct surfaces and two different learning domains which may be intriguing and effective for learners. The two interactive surfaces, one table-top and one floor-based, depict a journey performed by students via touching a 3D augmented tangible map, coupled with a robotics track where students perform a "Treasure Hunt" with a robotic companion. The goal of the study was to explore the learning effects of this multimodal tangible interface, which was constructed with lowcost and easy-to-find hardware, and which teachers and students can easily reproduce and transform to fit into multiple teaching scenarios. The study examined variables covered multiple dimensions relating to such a technological learning intervention: Cognitive tests to assess the efficacy of the learning paradigm coupled with usability and user acceptance questionnaires to assess the usability/motivational aspects (ease of use, autotelic experience, user stimulation and identity etc.). The present paper gives an outline of the relevant literature in section 2, describes the proposed scenario and learning environment in section 3, while in sections 4 and 5 we describe the details of the study and analyze our findings respectively.

\section{$2 \quad$ Literature Review}

The embodied cognition theory framework, postulates that acting and thinking are intertwined. The way we perceive objects or spaces is affected by the way we engage or explore them tangibly. Our mental representations are directly influenced by the physical world through our body. There are various frameworks which suggest that 
full-body interaction potentially supports learning by enabling user involvement at different levels (affective factors, cognitive aspects, sensorimotor experience). The building of new knowledge is based on conceptual anchors created by students who act out and "physicalize" processes and relationships [13]. Thus, new interaction technologies provide us with the ability to deploy embodied learning interventions that serve as conceptual leverage. New modalities are constantly being developed, following the precepts of embodied interaction. These environments aim to facilitate embodied experiences of specific concepts, represent abstractions as concrete instances or express specific content via the operationalization of actions. The use of educational robotics, mixed reality applications and tangible interfaces offers learning opportunities that need to be explored and exploited, since designing learning activities for such complex environments is an emerging area of research that is not adequately systematized yet.

Three research domains constitute the pillars of this study: a. Geography learning and tangible maps b. History learning and ICT and c. Tangible interfaces and educational robotics

Regarding tangible maps, literature suggests that both electronic and paper maps provide advantages but also limitations concerning the development of the students' spatial thinking skill [14]. But, since such maps are projected in two dimensions, there is an inherent limitation in their spatial topography, which hinders tasks such as asserting the visibility of a location or certain natural limitations, by forcing learners to perform mental calculations and topographical reconstructions [15]. Adding digital interaction capabilities to tangible 3D physical maps has greatly impacted contemporary cartography [16] and facilitated the learning of geography in an embodied context [6]. Continuous shape displays, where a digital model is paired with a physical one, 3D scanning and computation, provide a continuous feedback loop through which the student interacts in a natural and direct way with geophysical bodies, are being proposed as tangible interfaces for learning and are of special interest. The FingerTrips approach for teaching geography [6] has been shown to have positive results in improving the learning experience, in making it more interactive, and in facilitating understanding of geographical spatial and geophysical relations. In a pilot study with 58 4th grade students, the FingerTrips approach has transformed the experience of meeting new places, understanding spatial relations and learning geography, through a mixed reality tangible environment that uses embodied affordances. This approach was drastically different from the traditional geography-teaching paradigm followed in elementary schools, mainly through the gamification of learning and the tangible interactivity, which made the learning process fun and enjoyable.

Examining history learning, recent literature suggests that including ICT in teaching scenarios enhance students' motivation and enables the development of historical thinking skills [17] while transforming the experience of history learning to a constructive and explorative approach [18]. In the process of history teaching, applications centered on virtual worlds [17], and augmented reality[18] have been gaining traction in recent literature. Historical battles, ancient cities and civilizations come to life through the use of technology. Recent advances in technology enable educators to transfer their teaching paradigms from "static" representations of historical sites and acts, to representa- 
tions that include role playing capabilities that enhance immersion in the historical context (i.e. students can become "citizens" in the virtual city of Pompeii or soldiers in the battle of Thermopylae). Simulating historical events and projecting them on timeline applications helps learners to develop deeper understanding of the concept of time, of how historical events succeed each other and how historical knowledge is collected and recorded [19]. Digitally-enhanced experiences that offer interactive capabilities are being increasingly deployed by public installations and museums, transforming the visitors' experience to a highly multimodal engagement with the past [20]. There are few examples of embodied learning with tangible interfaces concerning history subjects. Recently, there is a trend to bring closer the classroom with historical installations through affordable and easily reconstructible augmented and embodied learning environments such as the FingerTrips approach, which apart from its geography application has also been used in the context of history teaching. In a recent study [9], the FingerTrips paradigm was deployed as an augmented 3D tangible model of a historical site, in which students could interact with historical content through a virtual field trip. The learning environment's effectiveness and efficiency was evaluated by twenty-six $6^{\text {th }}$ grade students who participated in the pilot. The students' answers revealed that FingerTrips enhanced their engagement and motivation in history learning, and made them feel as active participants in the historical event presented [9].

By including educational robotics to their teaching practice, educators can implement multiple educational approaches: discovery learning [21], collaborative learning [22], problem solving [23, 24], competition based learning [25] and compulsory learning [26]. Usually educational robotics is viewed as a subject mostly related to development of computational thinking [27]. Although this is of course the case, an educational robotics framework provides educators with a strong potential for multidisciplinary learning i.e. students can create a catapult as a prop for a tangible re-enactment of a historical battle or a water dam in the area the students inhabit [28]. There are also examples using robots alongside drones [29], or in conjunction with mixed reality/augmented environments and wearables [30]. There is now a rising trend for the development of multidisciplinary and multimodal teaching scenarios that combine robotics, tangibles and mixed reality applications in order to create authentic and immersive contexts through gamification of the learning process, following the precepts of experiential learning [31].

Elementary school children are fascinated by digital worlds. The advent of virtual reality and digital augmentation can provide exciting and immersive learning experiences -although the integration of this kind of interactive technologies into daily school routine is yet far away. Mixed Reality (MR) systems and highly interactive applications are very attractive to children which are extremely motivated and willing to play and work with novel affordances. Children may be actors inside a digital virtual world, but actually manipulate familiar physical things in the context of an interactive storytelling activity. Mixed Reality environments facilitate this merging offering immersive and vivid audio and visual interfaces that elicit bodily interaction. MR environments enable students to become integral parts of the system to be familiarized with, and give the 
opportunity to monitor and evaluate the underlying mechanisms and inherent relationships of the domain they are studying. [32]. Mixed reality environments can function as an umbrella under which multiple technologies can be combined.

\section{The Learning Environment}

In this study we tried to create a learning scenario for history, geography and computational thinking which combines the following design principles:

- Exploits embodied interaction with tangible objects

- Creates an immersive mixed reality environment in an authentic context where history and geography are intertwined with problem solving activities that also facilitate computational thinking and team work

- Creates a differentiated sequence of actions triggering the two modalities (FingerTrips and Robotics) and motivates students to interact with them

Our approach consists of two augmented spaces, which are conceptually linked, in our scenario, with students swapping between them as the "game" progresses. The game begins on a tabletop 3D augmented interactive map, deploying the FingerTrips approach: Students here are travelling on the map by using their fingers, either touching or following the relief of an embossed geomorphological path. Students move from city to city, passing over mountain ranges such as the Alps, the Pyrenees, the Apennines etc. During their journey, the environment stops them and poses questions or challenges that have to be answered for the game to continue. When reaching a major city or a historically significant destination, the environment prompts them to move to the second augmented space, the Robotics track: This space is floor-based, and here the students have to program their robots to perform specific tasks in a series of clue finding missions, employing a challenge-based learning scheme [34]. The background of the Robotics track each time depicts the city on which students have landed on the FingerTrips map. As soon as the teams have performed their robotics tasks, the clue is "found" and the students go back on the FingerTrips augmented map. The story of the activity is about a clue finding race around major European destinations. There are two teams of two students who must complete a variety of increasing difficulty tasks, which not only ask them to recall and apply prior knowledge, but also provide new information through a fun and embodied framework.

The Fingertip [6, 9] board was constructed from a 50x75cm MDF piece and the geophysiology of the terrain was constructed with plasteline. On this model, a vertically placed projector was overlaying the map and the questions of the game, as seen in Fig 1. The whole game was implemented in MIT Scratch and for the touch interface, we used a Makey-Makey board.

The floor-based robotics track consisted of an also vertically placed projector and a tarpaulin with dimensions of $1.5 \mathrm{~m} \times 1.13 \mathrm{~m}$ as seen in Fig 2. The robotics missions where implemented also in MIT Scratch and a second Makey-Makey was used to deploy touch-bases at the ends of each mission route. In that way, the game recorder not 
only the successful reaching of the mission goal but also the time it took for each team to correctly program the robot. In Fig 3, the full setup of the environment is presented.

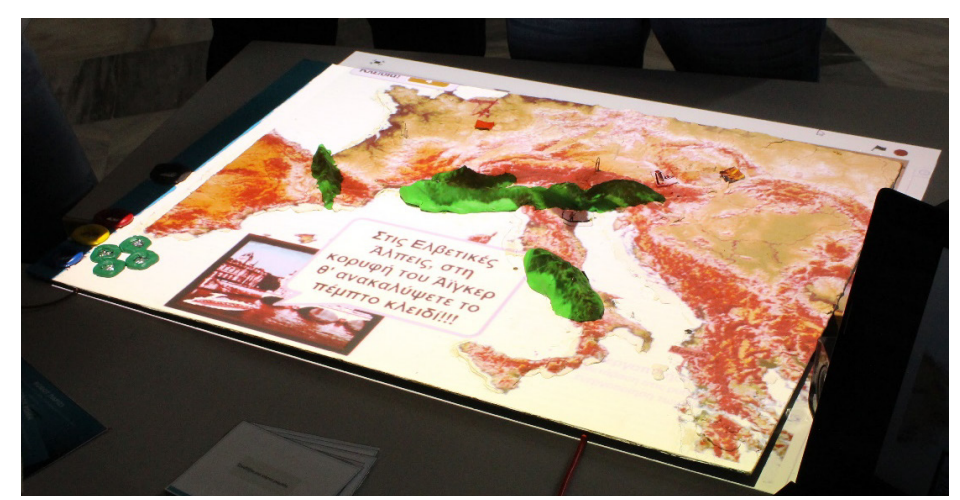

Fig. 1. FingerTrips Board

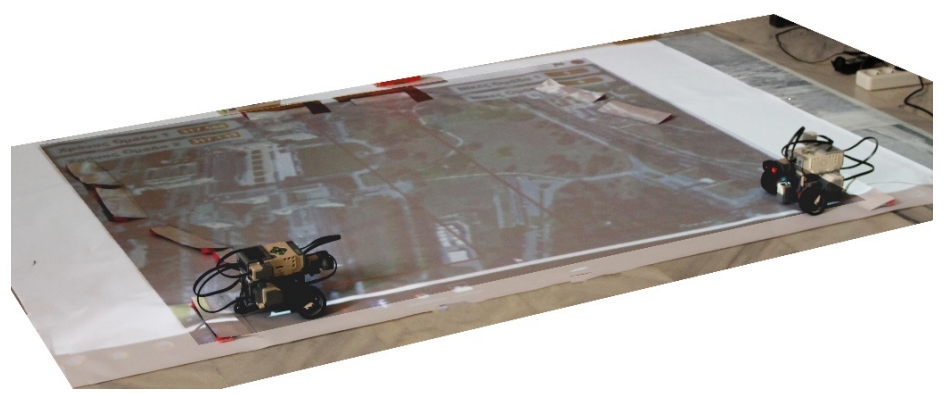

Fig. 2. Robotics track with EV3 explorers

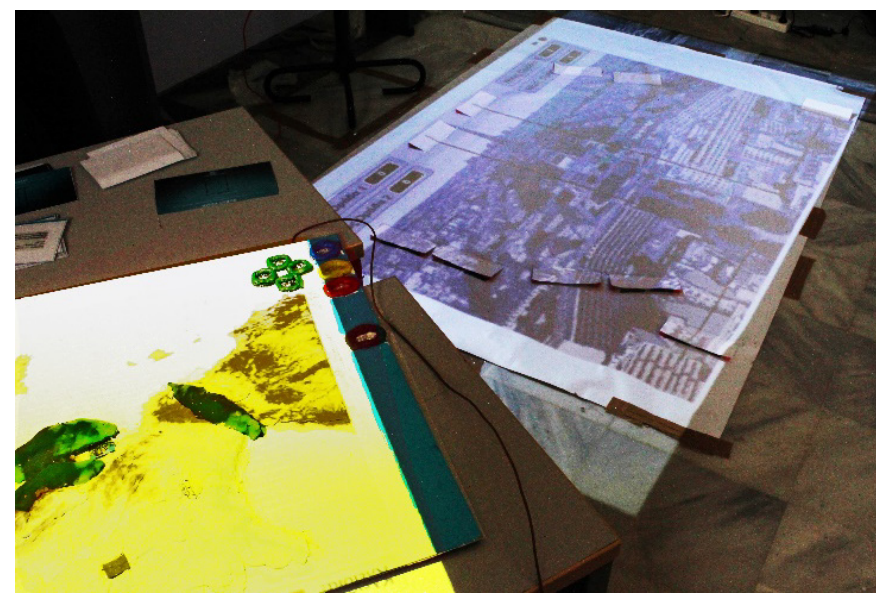

Fig. 3. Combined view 
The game session begins at the augmented 3D map, where all participants play as one team. The journey begins from Corfu and passes through 6 major European cities, exploring the whole routes in between, answering to questions, learning about historical landmarks or geographical information, and finding "clues" that point to the next city. In progression we map the whole progression of our intervention. The game prompts questions which are answered (by all participants) via a tangible interface.

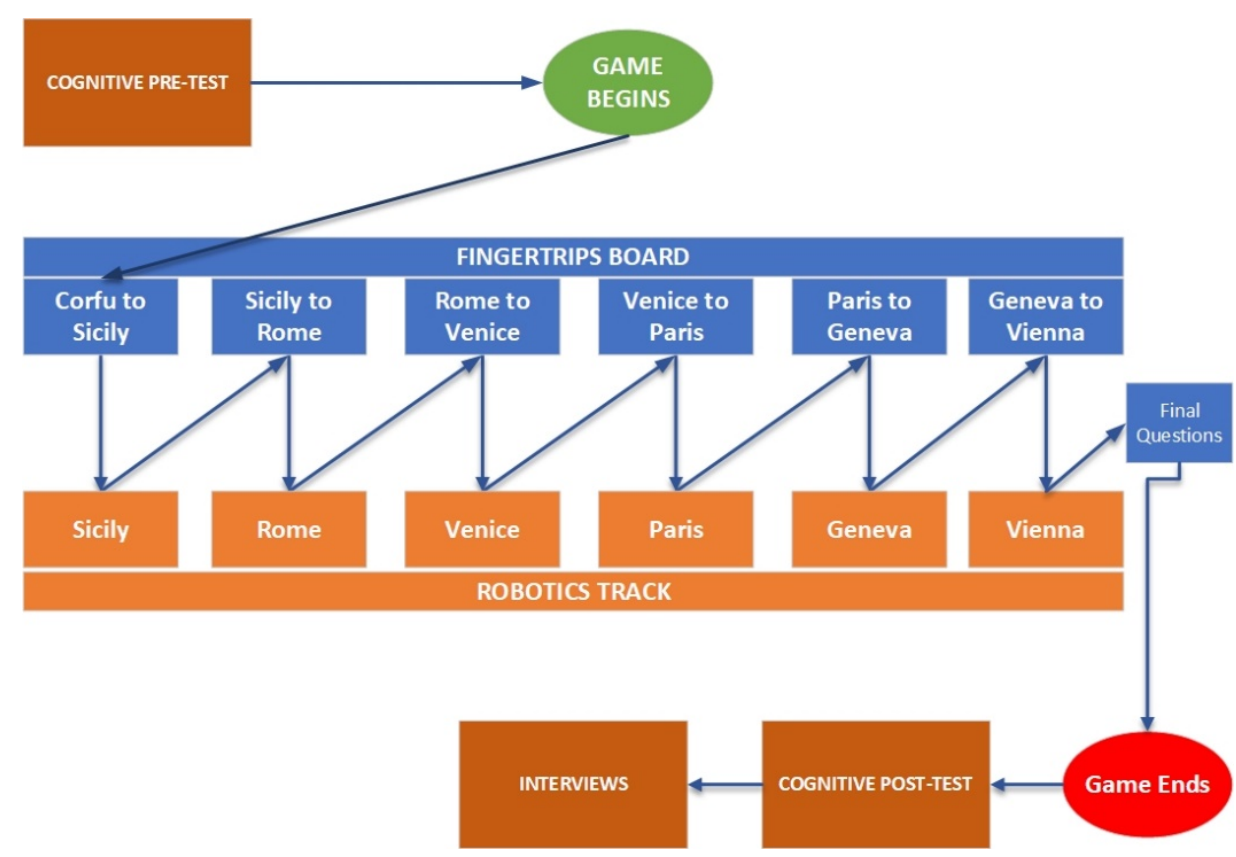

Fig. 4. Intervention progression

As soon as the team arrives at a major destination, participants break down into two teams and "turn against each other" hunting for clues with their robots on the floor based track. Their robots take the role of competing "Explorers" who search for clues in historical sites across Europe (Valle dei Tempi in Sicily, the Colosseum and the baths of Caracalla, piazza San Marco in Venice, etc.). Examples of the augmented space of the robotics track are depicted in Fig 5 Students must follow a projected route in each city and perform specific tasks with their Robot explorers in order to be able to proceed. The programming tasks are evolving from introductory lessons of moving forward/backward, to more advanced scenarios that require the use of sensors, in 4 separate stages. The robotics track is equipped with cardboard "touch-bases" which-detect whenever each robot reaches each destination. During all stages, programming instructions are provided to the students in the form of printed cards.

Thus, the intervention included a continuous exchange of activities, from traveling around Europe with FingerTrips to traveling in places with robots. 


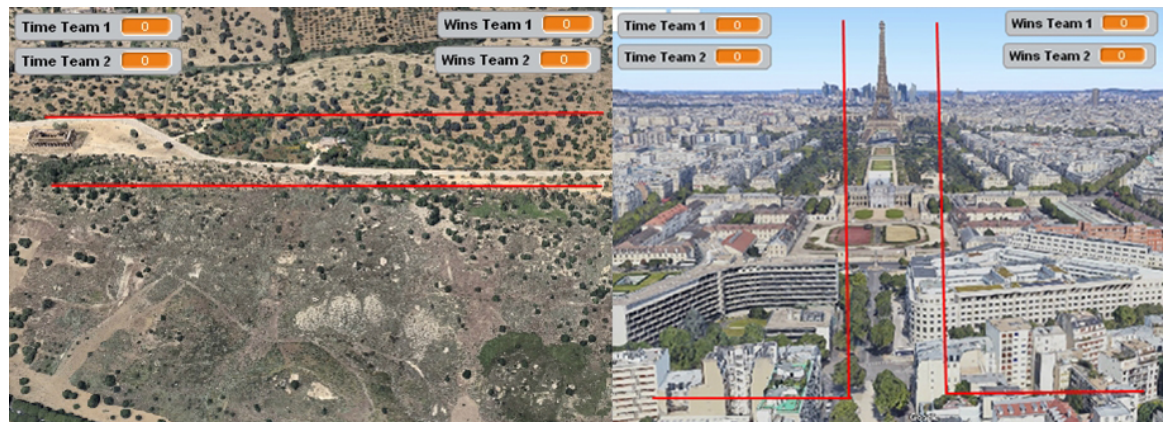

Fig. 5. The robotics track game with highlighted task routes. On the left, the Valley dei Tempi in Sicily and on the right the track in Paris

\section{The Study}

In order to evaluate the proposed environment, a study was conducted with pre-service school teachers. Pre-service school teachers do need to develop the related skills and knowledge and also seek for instructional interventions that are effective and intrigue the students.

\subsection{Participants}

Twenty-three (23) undergraduate students from a Department of Primary Education, 12 males and 11 females, exploited the FingerTrips and the augmented interactive floor environment. The undergraduates were in the second and third year of their studies and had previous teaching experience in public schools in the context of their practice. The students participated in the study as part of a voluntary activity in an Educational Technology course. The integration of mixed reality environments in the classroom is a demanding endeavor which requires the positive attitude of the teachers towards their expected effectiveness and efficiency. Future teachers' evaluations can reveal both the educational value of the proposed intervention and their intention to use it and it is a significant indicator of its viability.

The participants played in 6 (six) groups of 3 or 4 students while each session lasted about 45 minutes.

\subsection{Procedure}

Before starting the game, brief instructions were given to each group, to help students familiarize with the concept of interacting with the 3D interactive model. Guidance was offered by the researchers whenever the participants requested for. Pre- and post-knowledge tests were given immediately before and after the intervention. After completing their session, students completed an online questionnaire to evaluate their experience. Additionally, all students after the end of their sessions answered informal questions as part of a brief group interview. 


\subsection{Research instrument}

The evaluation of the environment was based on pre/post tests, an attitudes questionnaire and a semi-formal group interview. Pre and post-tests were identical and were consisted of twelve questions for spatial relations (i.e., Paris and the Alps are equidistant to the Equator, is Rome located south of Corfu?) and eight questions for information recall questions about geography and history (i.e., To which mountain range does Mont Blanc belong? Is Eiger mountain the highest of the Alps?). The scale of the test scores was 0 to 20 .

The questionnaire concerning students' attitudes consisted of twenty-five 7-point Likert questions ( 1 corresponded to total disagreement with the statement, 7 was related to total agreement) and focused on the usability and the attractiveness of the tangible environment. Several questions were extracted from AttrakDiff [35] which gauges how the attractiveness of an interactive environment is experienced, in terms of usability and appearance and Flow State Scale [36] which monitors whether an experience is genuinely satisfying. The following variables were evaluated:

- Ease of Use (3 questions): concerns how easy to use the system is and its learnability

- Autotelic experience (3 questions): concerns the extent to which the system offers internal user satisfaction

- Perceived learning (3 questions): concerns students' perceptions on the educational value of the system

- User Focus (3 questions): concerns the concentration during the use of the system

- The value of the proposed environment for practicing educational robotics (3 questions): concerns students' attitudes towards the learning environment as a platform for practicing development skills in educational robotics

- Pragmatic Quality (4 questions): concerns the extent to which the system allows a user to achieve his goals

- Hedonic Quality-Stimulation (3 questions): concerns the extent to which the system meets the user's need for innovation and whether it is of interest

- Hedonic Quality-Identity (3 questions): concerns the extent to which the system allows the user to identify with it

All variables can be considered as consistent since they had satisfactory Cronbach's a higher than 0.7 as seen in Table 2 .

The semi-formal interviews were conducted immediately after the end of each session in order to record a qualitative assessment of the system for each student and to allow them to express their personal view of their experience with the FingerTrips and Robotics virtual space. The questions sought to identify what students liked and disliked and how they perceived the learning efficiency and effectiveness of the environment. The recorded interviews were transcribed and afterwards encoded and compared within and between cases. Afterwards, the three researchers collaborated in order to reach consensus for the commonly identified issues. 


\section{$5 \quad$ Findings}

\subsection{Pre-post test results}

We applied the Shapiro-Wilk normality test in pre- and post- scores and both variables followed a normal distribution $(\mathrm{p}>0.05)$. Hence, paired samples t-test were conducted for the two variables and the results are presented in Table 1. The students scored significantly higher in the post-test and we can claim that the learning environment had provoked significant learning outcomes. Interestingly, students demonstrated higher scores both in spatial relations questions and in information recall questions as seen in Table 1. The environment helped them to develop their spatial awareness for the visited places and also to remember more details about them.

Table 1. Pre/Post test results

\begin{tabular}{|l|c|c|c|c|}
\hline & Pre Test Mean (SD) & Post Test Mean (SD) & t & Sig \\
\hline Information recall & $7.09(1.70)$ & $9.00(1.98)$ & -4.757 & .001 \\
\hline Spatial relations & $5.57(1.65)$ & $7.35(1.07)$ & -4.229 & .001 \\
\hline Total Score & $12.65(2.84)$ & $16.35(2.56)$ & -5.334 & .001 \\
\hline
\end{tabular}

\subsection{Students' attitudes towards the environment}

Students' answers to the attitudes questionnaire (see Table 2) show that the environment successfully addresses the issue of enabling engagement with the geographical and historical content. Students enjoyed interacting with the two interactive surfaces and were engaged to achieve the objectives set for them. For example, a great majority of the students supported that they would like to use similar environments often $(\mathrm{M}=6.39, \mathrm{SD}=.58)$, that they were totally focused in the required tasks $(\mathrm{M}=6.21$, $\mathrm{SD}=.92)$ and that their experience was enormously satisfying $(\mathrm{M}=6.74, \mathrm{SD}=.45)$.

Moreover, as also seen in Table 2, students provided positive feedback regarding the learning efficiency of the environment and the high potential of further exploitation in other university courses. For example, they supported that they prefer to learn about geography with the new approach $(\mathrm{M}=6.65, \mathrm{SD}=.57)$ and they believed that they can more efficiently and in shorter time than with traditional means $(\mathrm{M}=6.52, \mathrm{SD}=.67)$. The undergraduates were even more positive with the prospect of familiarizing with educational robotics by using similar environments $(\mathrm{M}=6.70, \mathrm{SD}=.64)$. However, they were positive but more reluctant about whether a primary school student could handle the environment's requirements $(\mathrm{M}=5.74, \mathrm{SD}=.76)$. This seemingly contradictory attitude can easily be explained, if we take into account the students' highly technological everyday experiences (especially considering their usually strong social media presence and use of mobile devices, applications, gaming habits etc.) and their background in theoretical sciences and humanities. Thus, the students are highly attracted to novel technological approaches in education, but also harbor insecurities regarding their ability to make the leap from user to creator of digital/technological content. 
Table 2. Attitudes Questionnaire Answers

\begin{tabular}{|l|c|c|c|c|c|}
\hline & Min & Max & Mean & SD & Cronbach's a \\
\hline Easiness & 5.33 & 7.00 & 6.28 & .55 & .73 \\
\hline Focus & 4.33 & 7.00 & 6.19 & .78 & .83 \\
\hline Autotelic Experience & 5.67 & 7.00 & 6.72 & .40 & .75 \\
\hline Learning Preference & 5.00 & 7.00 & 6.57 & .56 & .86 \\
\hline As a platform for learning robotics & 4.67 & 7.00 & 6.33 & .63 & .76 \\
\hline Pragmatic Quality & 5.00 & 7.00 & 6.13 & .58 & .71 \\
\hline Hedonic Identity & 5.00 & 7.00 & 6.54 & .57 & .82 \\
\hline Hedonic Stimulation & 4.67 & 7.00 & 6.62 & .59 & .72 \\
\hline
\end{tabular}

AttrakDiff questions indicated that the students considered that the provided functions of the environment are appropriate for reaching the goal of understanding both the geographical features and the historical information presented (pragmatic quality). Furthermore, the hedonic quality variable, as a measure of pleasure (original, fun engaging experience) and a measure of if boredom and discomfort are avoided had very high values. Students indicated that the environment succeeded in making them identify themselves with it (Hedonic Quality-Identity) and perceived that it offered novel and inspiring (Hedonic Quality-Stimulation). These two last findings reaffirm the fact that digital simulations and gamified contexts are particularly effective in developing empathy[37] -albeit in our case in a different context

\subsection{Interview results}

In the interviews, students validated the observations extracted from the analysis of the questionnaires. Students were particularly positive about the intervention and characterized the proposed environment as attractive, fun, playful, pleasant, and creative. This kind of activities and interaction styles address better their technological expectations and offer a more vivid, authentic and meaningful learning environment.

"It is a game that we will always be interested in playing."

"It is not a boring thing. Children learn much more easily."

Most students tried to explain the improved educational effectiveness of the proposed environment by comparing it with more typical and usual methods of learning about the domains under examination. They commented that the new approach is very different, more interesting and more motivating than typical learning in the classroom.

"I think it is a different experience to approach geography in this meaningful way, rather than simply looking at a map, a book or even a computer"

"It is much more different than traditional teaching and I would have preferred it $100 \%$ ".

Undergraduates underlined several times the qualities of their interaction with the map using their fingers. They characterized it as vivid, real, pleasant or helpful and considered the 3D finger trip as an interactive and intriguing experience. They pinpointed that it helped them

- Familiarize and understand better the details of the geomorphology of the map, 
- Identify and understand better the relative geographical positions of the different sites,

- Acquire an overall orientation on the specific map.

FingerTrip style of interaction together with the third dimension on the surface and the presented narration, gave life and meaning to the map, made the map touchable and attractive and brought the students closer to the sites of the scenario.

"It is like going through it [the journey] experientially, it's not just like watching the map, with the finger trip you can feel walking along the mountain ranges."

"I was troubled for example about the geographical location of Rome in relation to Corfu but with the help of the game I understood something I was not sure about."

"[Fingertrips are important] because if the map was flat we would not have to touch it with our fingers. We could not understand the morphology. Now, we were in contact with the mountains and the geographical relief."

"It helped us to understand the spatial relations."

"It also helped us in orienting ourselves around Europe."

The undergraduates also supported that the mixed reality environment was more interesting as a learning canvas for performing robotic missions than what usually happened in the laboratory course. In labs, the robots perform tasks on desks with artificial obstacles. In the interactive floor, the robots' missions were integrated in the overall scenario, while movement seemed to be taking place inside a real physical space. The interactive model recognized the success of the assigned task for each team, changed the score and the context of use and gave appropriate assistance to the two different groups. All these elements created a competitive culture that kept the students active and engaged.

"The robotics floor is interesting and more active, like an actual game".

"It certainly helps, in the lab we did everything on a desk, it was not the same in our thinking, the way we perceived it"

"The augmented robotics map gives the illusion of a real space"

"I loved that it kept score and measuring wins and losses. It was highly competitive and kept us active".

\section{Conclusion}

The results of the present study indicate that the proposed educational environment seems to improve the efficiency and the effectiveness of learning about history and geography while also may work as a platform for advancing students' computational thinking skills. The approach is significantly differentiated from traditional means of learning and is closer to students' highly interactive technological environment. The proposed setting engaged and kept students motivated by gamifying learning using embodied affordances. Students claimed that the two augmented spaces gave life to the two different learning domains and promoted an active and participatory process of learning. Tangible interfaces and mixed reality environments are inherently social and authentic contexts of technological use and the undergraduates suggested that teams' collaboration and competition over augmented layers of reality made learning much 
more interesting and fun, in comparison with the "purposeless" or "dull" tasks in artificial laboratory settings.

Our approach could be discerned

- By the multi-surfaces it offers since it involves more than one interactive workspace

- By the multi-sensory students' involvement since it requires students to interrelate with the learning material with different senses

- By the interdisciplinary approach that it exploits. This is a significant departure from monolithic technological interventions and it projects more complex and intriguing contexts of future educational technology. Moreover, we should underline that the proposed intervention was designed keeping in mind that it should be affordable and easy to make. Both the 3D map and the robotics track were made from cheap and accessible materials. Robotics sets, projectors and Makey-Makey sets are by now part of many schools' equipment and, hence, elementary school teachers and students can use similar approaches in order to deploy multidisciplinary learning scenarios for different learning subjects.

The presented study has several limitations, the foremost being the small sample of participating students. A second issue is the lack of analysis of the apparent underlying embodied learning mechanism. A third issue is that it should be validated in long term contexts. New studies, with more sessions should be done to further assess how and if similar multimodal and multi-technology environments can improve and enhance the learning process while making it enjoyable.

\section{$7 \quad$ References}

[1] G. Boadu, "An examination of the use of technology in the teaching of history. A study of selected senior high schools in the Cape Coast Metropolis, Ghana" International Journal of Learning, Teaching Educational Research and Reviews, vol. 8, no. 1, 2014.

[2] A. Kitson, C. Husbands, and S. Steward, Teaching and Learning History, 11-18: Understanding the Past. McGraw-Hill Education (UK), 2010.

[3] J. D. Nokes, "Recognizing and Addressing the Barriers to Adolescents: Reading Like Historians." The history teacher, vol. 44, pp. 379-404, 2011.

[4] D. Giannopoulos, " Italian Presence in the Dodecanese 1912-1943: Teaching a History Topic in Weebly Environment. Procedia Computer Science, vol. 65, pp. 6176-181, 2015.

[5] A. Baker, Geography and History - Bridging the divide. . Cambridge university press, 2003.

[6] G. Palaigeorgiou, A.Karakostas, K. Skenderidou, "FingerTrips: Learning Geography through Tangible Finger Trips into 3D Augmented Maps," in 17th International Conference on Advanced Learning Technologies (ICALT), 2017, pp. 170-172: IEEE.

[7] J. H. Bickford, "Initiating Historical Thinking in Elementary Schools," Social Studies Research and Practice vol. 8, pp. 60-77, 2013.

[8] M. Mpiladeri, G. Palaigeorgiou, and C. Lemonidis, "Fractangi: A Tangible Learning Environment for Learning about Fractions with an Interactive Number Line," in International Conference on Cognition and Exploratory Learning in the Digital Age (CELDA), 2016: International Association for Development of the Information Society. 
[9] I. Triantafyllidou, A.-M. Chatzitsakiroglou, S. Georgiadou, and G. Palaigeorgiou, "FingerTrips on tangible augmented 3D maps for learning history," in Interactive Mobile Communication, Technologies and Learning, 2017, pp. 465-476: Springer.

[10] D. Robert, R. Wistorrt, J. Gray, and C. Breazeal, "Exploring mixed reality robot gaming," in Proceedings of the fifth international conference on tangible, embedded, and embodied interaction, 2011, pp. 125-128: ACM.

[11] A. Eguchi, "Computational thinking with educational robotics," in Society for Information Technology \& Teacher Education International Conference, 2016, pp. 79-84: Association for the Advancement of Computing in Education (AACE).

[12] S. Atmatzidou and S. Demetriadis, "Advancing students' computational thinking skills through educational robotics: A study on age and gender relevant differences," Robotics and Autonomous Systems vol. 75, pp. 661-670, 2016. https://doi.org/10.1016/j.robot.2015.10.008

[13] R. Lindgren, M. Tscholl, S. Wang, and E. Johnson, "Enhancing learning and engagement through embodied interaction within a mixed reality simulation," Computers in education, pp. 174-187, 2015.

[14] L. Collins, "The impact of paper versus digital map technology on students' spatial thinking skill acquisition," Journal of Geography, vol. 117, no. 4, pp. 137-152, 2018. https://doi.org/10.1080/00221341.2017.1374990

[15] N. Li, W. Willett, E. Sharlin, and M. C. Sousa, "Visibility perception and dynamic viewsheds for topographic maps and models," in Proceedings of the 5th Symposium on Spatial User Interaction, 2017, pp. 39-47: ACM.

[16] A. Petrasova, B. Harmon, V. Petras, and H. Mitasova, Tangible modeling with open source GIS. Springer, 2015.

[17] A. Bogdanovych, K. Ijaz, and S. Simoff, "The city of uruk: teaching ancient history in a virtual world," in International Conference on Intelligent Virtual Agents, 2012, pp. 28-35: Springer.

[18] Y. Blanco-Fernández, M. López-Nores, J. J. Pazos-Arias, A. Gil-Solla, M. Ramos-Cabrer, and J. García-Duque, "REENACT: A step forward in immersive learning about Human History by augmented reality, role playing and social networking," Expert Systems with Applications, vol. 41, no. 10, pp. 4811-4828, 2014. https://doi.org/10.1016/j.eswa.2014.02.018

[19] J. G. Galán, "Learning historical and chronological time practical applications," European Journal of Science and Theology, vol. 12, no. 1, pp. 5-16, 2016.

[20] G. M. Savenije and P. de Bruijn, "Historical empathy in a museum: uniting contextualisation and emotional engagement," International Journal of Heritage Studies, vol. 23, no. 9, pp. 832-845, 2017. https://doi.org/10.1080/13527258.2017.1339108

[21] F. R. Sullivan and M. A. Moriarty, "Robotics and discovery learning: Pedagogical beliefs, teacher practice, and technology integration," Journal of Technology Teacher Education, vol. 17, no. 1, pp. 109-142, 2009.

[22] B. Denis and S. Hubert, "Collaborative learning in an educational robotics environment," Computers in Human Behavior vol. 17, no. 5-6, pp. 465-480, 2001. https://doi.org/10.1 016/S0747-5632(01)00018-8

[23] D. Alimisis, S. Frangou, and K. Papanikolaou, "A constructivist methodology for teacher training in educational robotics: The TERECoP course in Greece through trainees' eyes," in 2009 Ninth IEEE International Conference on Advanced Learning Technologies, 2009, pp. 24-28: IEEE.

[24] V. Ilieva, "Robotics in the primary school-How to do it," in Proc. Int. Conf. on Simulation, Modelling and Programming for Autonomous Robots, Darmstadt, Germany, 2010, pp. 596605. 
[25] A. Eguchi, "RoboCupJunior for promoting STEM education, 21st century skills, and technological advancement through robotics competition," Robotics and Autonomous Systems

[26] vol. 75, pp. 692-699, 2016.

[27] A. Khanlari, "Teachers' perceptions of the benefits and the challenges of integrating educational robots into primary/elementary curricula," European Journal of Engineering Education, vol. 41, no. 3, pp. 320-330, 2016. https://doi.org/10.1080/03043797.2015.1056106

[28] E. Afari and M. Khine, "Robotics as an educational tool: impact of lego mindstorms," Journal of Information and Education Technology, vol. 7, no. 6, pp. 437-442, 2017. https://doi.org/10.18178/ijiet.2017.7.6.908

[29] W. Challenges. (2014, 13.Jan.2019). The great catapult | Dr. E's WeDo Challenges. Available: https://wedo.dreschallenges.com/the-great-catapult/.

[30] G. Palaigeorgiou, G. Malandrakis, and C. Tsolopani, "Learning with Drones: flying windows for classroom virtual field trips," in 2017 IEEE 17th International Conference on Advanced Learning Technologies (ICALT), 2017, pp. 338-342: IEEE.

[31] W. Hoenig, C. Milanes, L. Scaria, T. Phan, M. Bolas, and N. Ayanian, "Mixed reality for robotics," in 2015 IEEE/RSJ International Conference on Intelligent Robots and Systems (IROS), 2015, pp. 5382-5387: IEEE.

[32] C.-Y. Wang, C.-H. Chen, C.-J. Wu, Y.-L. Chi, J.-H. Lee, and G.-D. CHEN, "Constructing a digital authentic learning playground by a mixed reality platform and a robot," in Proceedings of the 18th International Conference on Computers in Education, 2010, pp. 121-128.

[33] R. Lindgren and M. Johnson-Glenberg, "Emboldened by embodiment: Six precepts for research on embodied learning and mixed reality," J Educational Researcher, vol. 42, no. 8, pp. 445-452, 2013.

[34] D. Markouzis and G. Fessakis, "Rapid Prototyping of Interactive Storytelling and Mobile Augmented Reality Applications for Learning and Entertainment-The Case of " $\mathrm{k}$ Knights"," International Journal of Engineering Pedagogy, vol. 6, no. 2, pp. 30-38, 2016. https://doi.org/10.3991/ijep.v6i2.5560

[35] W. B. Gaskins, J. Johnson, C. Maltbie, and A. Kukreti, "Changing the learning environment in the college of engineering and applied science using challenge based learning," International Journal of Engineering Pedagogy vol. 5, no. 1, pp. 33-41, 2015. https://doi.org/10.3 991/ijep.v5i1.4138

[36] M. Hassenzahl and A. Monk, "The inference of perceived usability from beauty," Journal of Human-Computer Interaction, vol. 25, no. 3, pp. 235-260, 2010. https://doi.org/10.1 $\underline{080 / 07370024.2010 .500139}$

[37] S. A. Jackson and H. W. Marsh, "Development and validation of a scale to measure optimal experience: The Flow State Scale," Journal of sport exercise psychology, vol. 18, no. 1, pp. 17-35, 1996. https://doi.org/10.1123/jsep.18.1.17

[38] C. Papoutsi and A. Drigas, "Games for Empathy for Social Impact," International Journal of Engineering Pedagogy vol. 6, no. 4, pp. 36-40, 2016. https://doi.org/10.3991/ijep.v6i4.6064

\section{Authors}

Stefanos Xefteris studied Mathematics in the Aristotle University of Thessaloniki and completed his Ph.D at the National Technical University of Athens, Greece. Since February 2017 he has been working as an adjunct lecturer at the Department of Primary Education of the University of Western Macedonia, Greece. His research interests are educational robotics, tangible interfaces, mixed and augmented reality applications in education. 
George Palaigeorgiou is Assistant Professor in Department of Primary Education in University of Western Macedonia, Greece. He holds a Ph.D. in Students-Computer Interaction from the Informatics Department of Aristotle University of Thessaloniki, an MBA and a BS in Computer Science. His research interests include tangibles, mixed reality environments, participatory design, interactive video and computer ethics.

This article is a revised version of a paper presented at the International Conference on Interactive Collaborative Learning (ICL2018), held September 2018, in Kos, Greece. Article submitted 2018-11-30. Resubmitted 2019-03-03. Final acceptance 2019-03-05. Final version published as submitted by the authors. 